\title{
Overview of Child Malnutrition at Katima Mulilo Hospital (Zambezi Region/Namibia)
}

\author{
Article by Amisi Bitoma \\ MD (Unikin/DR Congo), PG Dip FamMed (SU/SA), Congo \\ E-mail: tamisi2003@yahoo.fr
}

\section{Introduction}

Malnutrition among children is very common in developing countries. Malnutrition is a physical state in which physical function of an individual is impaired to the point at which he or she can no longer maintain adequate bodily performance processes (growth, pregnancy, lactation, physical work, and resisting or recovering from diseases.) (1).

Malnutrition presents a double burden in the world currently.

1. Severe acute wasting Malnutrition also called thinness (2) which is fast or rapid wasting of body weight [weight for height ratio below $<-3$ standard deviation (SD)] or bilateral nutritional edema.

2. Severe overweight also called Obesity (3) which is defined as excess body fat deposited in the body contributing to comorbidity. Body Mass Index (BMI) is the measurement of obesity [when BMI is > 30 or when waist circumference is $>88 \mathrm{~cm}$ (Female) and $>102 \mathrm{~cm}$ (Male), there is obesity].

Severe acute wasting Malnutrition and obesity are all conditions that have an impact on a Public Health Point of view.

Indeed, according to the data published by UNICEF, WHO and World Bank Group in 2015 (4):

- Stunting also called shortness (meaning chronic malnutrition based on height per age ratio) are dropping but 159 million children around the world are still affected.

- There are 41 million overweight children in the world, about 10 million more than there were 2 decades ago.

- Wasting still threatens the lives of 50 million children across the globe.

- The majority of children under 5 suffering from wasting live in Asia. In 2015 , 34,3 million wasted children under 5 were from Asia which represent $68 \%$ of the globally number of wasted children under 5(Southern Asia being the house to more than half of all wasted children under 5 globally) (4). Africa is the second worst continent with the second higher number of wasted children under 5 which is around 13,9 million ( $28 \%$ of the global number) (4).

$57 \%$ of world stunted children are from Asia while $37 \%$ of world stunted are from Africa mostly in Eastern Africa, Middle Africa and Western Africa. (4).

Low income and lower middle income countries are the majority of countries that experience more of wasting and stunting among children under 5(4).

Namibia is one of the Southern African Countries with a small number of the population (+/- 2 million according to the latest census done in 2011). Namibia is among the countries in the world with a high prevalence of HIV infection. According to Namibia HIV Sentinel Survey 2016 (5), the prevalence of HIV in Namibia is $17.2 \%$. Katima Mulilo, the main town of Zambezi region has the highest prevalence of the HIV in the whole Namibia which is $32.9 \%$ (Near to 1 among 3 persons of Katima mulilo has HIV).

Namibia is among the countries with lower middle income countries in the Southern Africa (6). HIV is the main health problem with Tuberculosis. Malnutrition has never been pointed among the major health problems in Namibia. As a Medical officer at Katima Mulilo District Hospital, the only one hospital in Katima Mulilo Town and the whole Zambezi Region (one among the 13 regions of Namibia), I have decided to look at the number of cases of severe Malnutrition among children in Zambezi Region knowing that, being a worker at the unique hospital of Zambezi region, most of the severe cases of Malnutrition will be referred to Katima Mulilo Hospital (unless if the patient recovers fast or dies before arrival to the 
DOI: $10.21522 / \mathrm{TIJPH} .2013 .05 .04$. Art019

ISSN: $2520-3134$

hospital). This article is an overview of severe malnutrition among children in Katima Mulilo (via Katima Mulilo Hospital) particularly and by extension in the whole Zambezi Region in general.

\section{Literature review}

\section{Summary of knowledge about child malnutrition}

Malnutrition is still a public health problem in developing countries mostly (Africa and Asia mainly). Even in developed countries, malnutrition cases are still recorded.

According to UNICEF, WHO, World Bank Group joint Malnutrition estimates, 2015 Edition (4), in 2014 , the global wasting rate was $7.5 \%$. Approximately 1 out of every 13 children in the world was wasted in 2014.Nearly a third of all wasted children were severely wasted with a global prevalence in 2014 of $2.4 \%$. In 2014, there were 667 millions children under 5 in the world. An estimated 159 million were stunted, while 41 million were overweight and 50million children under 5 were wasted. Globally 50 million children under 5 were wasted of which 16millions were severely wasted in 2014. (4)

According to the article titled. "Global Nutrition Policy Review: What does it take to scale up nutrition action? " (7) , in May 2012 , the world Health Assembly (WHA) adopted a resolution (WHA 65.6) that endorsed the comprehensive Implementation Plan in Maternal, Infant and Young Child Nutrition which includes six global targets for 2025 (WHO 2012).

1. $40 \%$ reduction in childhood stunting

2. $50 \%$ reduction in anaemia in women of reproductive age.

3. $30 \%$ decrease of low birth weight.

4. $0 \%$ increase in childhood overweight

5. An icrease in the rate of exclusive breatfeeding in the first 6 months to at least $50 \%$.

6. A reduction of childhood wasting to less than $5 \%$

The vicious cycle of malnutrition and infection disease is well recognized; that is foodborne and the infection disease can cause malnutrition and malnutrition exacerbates infection. (7)

It has been estimated that undernutrition is an underlying cause in $35 \%$ of child deaths. (7)

The cut off value for a prevalence that is considered to be of public health significance are superior or equal to $20 \%$ for stunting, superior or equal to $10 \%$ for underweight and superior or equal to $5 \%$ for wasting (WHO, 1995) (7).

According to the article titled: "Level and Trends in Child Malnutrition, Unicef-WHO-The World Bank Joint Child Malnutrition estimates "(8) launched in 2012, it is highlighted that:

- Namibia is among the countries with severe Malnutrition (wasting) under 5 years rate that varies between 5 and $9.9 \%$.(8).

- Namibia is among the countries with underweight under 5 years rate that varies between 10 and 19.9 $\% .(8)$.

- Namibia is among the countries with stunting under 5 years rate that varies between 20 and 29.9\%.(8).

According to the United States Agency for International Development (USAID) (9), malnutrition and food insecurity are endemic in Africa. (9) Underweight, an indicator of chronic and acute malnutrition was the leading cause of mortality worldwide responsible for 3.7 million deaths in 2000.(9) The effects of malnutrition on the immune system are well known and include decreases in CD4 T-cells, suppression of delayed hypersensitivity and abnormal B-Cell responses. The immune suppression caused by proteinenergy malnutrition (PEM) is similar in many ways to the effects of HIV Infection (9).

HIV infection increases energy requirements. Asymptomatic HIV Positive individuals require $10 \%$ more energy and symptomatic HIV Positive individuals require 20-30\% more energy than HIV -Negative individuals of the same age, sex and physical activity level. (9)

The impact of pre-existing malnutrition on HIV susceptibility and disease progression is difficult to study, and knowledge in this area is still limited (9). 
Early studies demonstrated that weight loss and wasting were associated with increased risk of opportunistic infections and shorter survival time in HIV Positive adults, independent of their immune status.(9)

Other studies showed that clinical outcome was poorer and risk of death was higher in HIV Positive adults with compromised micronutrients intake or status. Micronutrient deficiencies may contribute to disease progression of HIV (9) Antiretroviral therapy (ARV) improves nutritional status but ARVs may also have side effects and metabolic complications. (9)HIV exposure and infections exacerbates problem of child malnutrition. (9)HIV exposed infants may start life with impaired nutrition. HIV Positive infants experience slower growth and are at greater risk of severe malnutrition.

Studies showed that severe malnutrition in HIV Positive children can be reversed with hospital and Home based therapeutic feeding, though the time for recovery is longer than with uninfected children.(9)

Periodic Vitamin A supplementation reduces morbidity and mortality in HIV Positive Children and improves their growth. (9)

\section{Presentation of zambezi region and katima mulilo hospital}

Namibia is a lower middle income country (6) which has 13 regions with a population of 2113077 habitants .(10) Zambezi Region has a population of 90596 habitants.(10)(11) Zambezi region is the second poorest region of Namibia.(11) Zambezi Region has only 1 district hospital named Katima Mulilo Hospital. There are 25 clinics and 3 health Centre in the region.

In this research ,our attention has been drawn to severe malnourished children admitted at Katima Mulilo in order to check whether all the literature review as presented above applies or not to malnourished children at Katima Mulilo particularly and Zambezi Region in general, more especially to answer to the following:

- Does Severe Malnutrition a burden or common condition among children at Katima Mulilo (by extension in the whole Zambezi Region)? In other words, can we consider malnutrition a rare condition among children at Katima Mulilo (by extension in the whole Zambezi Region)?

- Does gender a risk factor or a contributing factor for severe malnutrition among children in Katima Mulilo (by extension in the whole Zambezi Region? In other words, does Severe Malnutrition affects more females or more males (or it doesn't matter whether male or female) among children?

- Does HIV condition a more predisposing factor to poor prognosis or bad outcome of Severe Malnutrition (such as complications, deaths,...) compared to Free HIV children with severe malnutrition among children?

- Does infection or any other co-existing condition (except HIV) more present in Severe Malnutrition among children?

- Does severe malnutrition being costly to manage regarding the duration of admission (stay) in the hospital?

\section{Research methodology}

\section{Health service distribution in zambezi region}

Katima Mulilo is the main town of the Zambezi Region. Its population is estimated to be of 28362 habitants according to the latest census done in 2011(10).Zambezi region has 7 constituencies (11). The region has 25 clinics and 3 health centers. All these clinics and health centers refer their patients for further management at Katima Mulilo District Hospital, the unique hospital in the whole Zambezi Region.

- Katima Mulilo Hospital has 300 beds which are found in 5 wards :

- Maternity Ward.

- Pediatric Ward.

- Male Ward.

- Female Ward.

- Special Tuberculosis Ward (for isolation of patients diagnosed with Pulmonary Tuberculosis).

- The Pediatric Ward is the one receiving all severe malnourished children. 
DOI: $10.21522 / \mathrm{TIJPH} .2013 .05 .04$. Art019

ISSN: $2520-3134$

- Katima Mulilo Hospital being the only one hospital in Zambezi Region, all cases of severe malnutrition that needs hospital admission will definitely be brought at Katima Mulilo Hospital for further management.

- The results of the research will come from Katima Mulilo Hospital (Pediatric Ward).

\section{Research design}

This is a descriptive research that has been done.

The attention was drawn to the severe malnourished children admitted at Katima Mulilo State Hospital from the $1^{\text {st }}$ January 2017 to the $13^{\text {th }}$ August 2017, this means during the 225 first days of the year 2017. Most of the researches done on malnutrition look after the children under 5 years but for the sake of easy statistics, the population used in this research are all children admitted with the diagnosis of severe malnutrition. These children admitted in the Pediatric are aged from neonatal age to the age below 12 years old.

These children admission notes were collected and studied thoroughly in order to give responses to the five questions that motivated this research.

This job was done by 2 nurses of Pediatric ward and myself from the collection of data to the analysis of data.

\section{How was the collection of data done?}

At Katima Mulilo Hospital, the details of the patients on admission are not yet entered and stored in the computer. The details of the patient are entered manually in writing in an admission/discharge register book. From the register book, patients admitted with a diagnosis of severe malnutrition could have been identified (as well as those who could have got the final diagnosis of severe malnutrition while in the ward but were admitted with another diagnosis).

From the register book, the names of the patients are written and stored. Then, comes now, the research of the file of each patient in order to go through and look for other details of the patient during his/her admission.

\section{Weakness of the process of collection of data}

The process of collection of data was not easy. Some files were not having all the details of the patients. Many patients treated for malnutrition were not having their HIV status mentioned in their file. Does it mean that those patients were HIV and already on treatment? No one can be able to answer to that question.

Does it mean that those patients were HIV negative and there was no need to mention because of the good progress of the general condition? No one is able to give an answer.

Some patients were having their blood results (Full Blood Count or Liver Function test or Kidney function test,...).All these are some of the challenges noted during the collection of the data. All these issues were taken into consideration in the analysis of data where it was necessary.

\section{Data analysis and interpretation}

\section{Does malnutrition a burden or a common condition in katima mulilo hospital (and the whole zambezi region)}

From the $1^{\text {st }}$ January to the $13^{\text {th }}$ August 2017.

- 843 children have been admitted in the pediatric ward.

- Among the 843 children admitted, 76 of them were having severe malnutrition.

- Among the 76 severe malnourished children, 21 children died of severe malnutrition.

- The rate or percentage of case of malnutrition during the period of the study is: (76:843) $\mathrm{x} 100=9.0154 \%$.

- The rate or percentage of death among severe malnourished children is: $(21: 76) \mathrm{X} 100=27.6315 \%$. 
If we consider the children admitted at the Pediatric Department from $1^{\text {st }}$ January to $13^{\text {th }}$ August 2017 as a community, then we can easily say that:

1. $9 \%$ of the patients admitted at the pediatric department is a severe malnourished child.

2. Among 11 children admitted in the pediatric department is a severe malnourished child.

3. WHO has put a cut - off value of a percentage inferior or equal to $5 \%$ of wasting (severe malnutrition) among children (7). This shows that the rate of wasting (9.0154\%) is above the cut-off value. It is alarming because it is a poor result on a public health point of vue (12).

4. Near to $28 \%$ of severe malnourished children are dying at Katima Mulilo Hospital.

More than 1 among 4 severe malnourished end up dying. In another words, near to 3 among 10 severe malnourished are dying. This is a result that is unacceptable according to WHO (13). There is need of improvement in the awareness about malnutrition and aggressive management of the cases.

- Does gender a risk factor or contributing factor in Malnutrition among children?

- Among the 76 severe malnourished children, 21 of them died.

- Among the 21 lost, 14 children were male and 7 children were female.

- Among the 55 children who survived, 28 children were male while 27 children were female.

Based on these data, these are the followings:

1. $2 / 3$ of dead severe malnourished children are male while $1 / 3$ of dead severe malnourished children are female.

This means that among 3 severe malnourished children who die 2 are male.

2. Among the children who survived and were later discharged, there is no significant difference although the male are having 1 more severe malnourished children than female.

3. When we put together all the children with severe malnutrition, those who died and those who survived, the males are 42 while the females are 34.

This shows that more male suffer of severe malnutrition among children. Death among children who are severe malnourished is more with male than female (male are more fragile than female and die more than female). But among those who recover, there is no a very significant difference among males and females despite the fact that male are still leading slightly.

\section{Does HIV condition a more predisposing factor to poor prognosis or bad outcome of severe Malnutrition}

It is important to acknowledge that regarding this specific question, the data that was collected was not very complete. Indeed, among the 21 children lost with severe malnutrition, only 7 were having their HIV status recorded in their files. Unfortunately, it was not possible to make a follow-up at the level of parents. This would have brought a big financial burden knowing that some of the parents to the children were coming from remote villages across the Zambezi Region.

But, when we consider the HIV status of the 7 dead children, 5 of them were HIV negative while only 2 among them were HIV Positive. One of the HIV negative was born from an exposed mother (HIV Positive mother). One among the 2 HIV Positive children was still not yet on antiretroviral medications (ARV).

Among the children with severe malnutrition who survived, 36 of them were not carrying their HIV Status in their file. This means that their HIV Status was unknown or not recorded. Among the 19 remaining children with known HIV status, 13 of them were HIV Negative while only 6 were HIV Positive.

In conclusion, in regard to the HIV status, among the 76 children who were severe malnourished : 50 were not having their HIV status recorded, 26 were having their HIV Status recorded, 8 were HIV Positive and 18 were HIV Negative.

This means among the children with a known HIV Status, $(8: 26) \mathrm{X} 100=30.7692 \%$ were positive, (18: 26) $\mathrm{X} 100=69.2307 \%$ were negative.

These results are clearly showing that even HIV negative children malnourished as well HIV positive malnourished children die of malnutrition regardless of their negative HIV Status. HIV Negative as well HIV Positive children are affected by Severe malnutrition. Literature have clearly mentioned that HIV 
DOI: $10.21522 / \mathrm{TIJPH} .2013 .05 .04$. Art019

ISSN: $2520-3134$

infection worsens Malnutrition which is true(9), but the study done in Katima Mulilo Hospital didn't show a significant difference in the outcome of Severe Malnutrition with co-existing HIV Positive infection in comparison with Severe Malnutrition without co-existing HIV Infection.

One of the reasons behind the fact that some children were not having any result of their HIV Status is the fact that some children had a very fast worsening of the condition that the possibility of getting the HIV test done was not possible. Some of the children who died didn't even spend a full day at the Pediatric Ward.

Another reason behind the fact that some children were not having any result of their HIV Status could be the fact that some of the children had a fast good progress that, probably there was no urgency to do the HIV Test.

Some of the children had probably their HIV Status known and written in their Health Passport (the equivalent of a health note book for consultation in Namibia).

\section{Does infection or any other co-existing condition more present in severe malnutrition?}

Among children with severe malnutrition who lost their life, 13 among 21 children were suffering also of Gastro-enteritis and Dehydration (60.9047\%).2 other children were not having any other condition except the severe malnutrition (9.5238\%). 2 other children were having Pulmonary Tuberculosis (9.5238\%). 2other children were having Anemia (9.5238\%).1 child was also having hydrocephalus (4.7619\%) while another child was having Pneumonia (4.7619\%).

Among children with severe malnutrition who survived, 25 among 55 were suffering also of Gastroenteritis with or without dehydration (45.4545\%).12 other children were not having any other condition beside severe malnutrition $(21.8181 \%)$. 5 children were also suffering with Pneumonia $(9.0909 \%)$. 2 other children were having dermatitis $(3.6363 \%)$, 2other were suffering of Bronchopneumonia (3.6363\%) and 2 other children were suffering of Pulmonary Tuberculosis (3.6363\%). The last 7 children were having each one of these conditions: Bacterial conjunctivitis, hydrocephalus, Upper Respiratory Tract Infection, para phimosis, Down Syndrome, Otitis Media and Anemia.

When the children with severe malnutrition (wasting), those who died and those who survived are put together, the number of patient with Gastroenteritis is now 38 among 76 (50\%). This is the most co-existing condition with Severe Malnutrition. 4 children were suffering of Pulmonary Tuberculosis (5.2631\%) while 6 other children were suffering of Pneumonia (7.8947\%).14 other children were not having any other conditions while suffering of Severe Malnutrition (18.4210\%). Anemia was found among 3 children $(3.9476 \%)$. Bronchopneumonia was found among 3 children (3.9476\%). Hydrocephalus was found among 2 children (2.6315\%).Dermatitis was found among 2 children $(2.6315 \%)$. The last 4 children were having each one of these conditions: Upper Respiratory Tract Infection (URTI), para phimosis, Down Syndrome and Otitis Media. (1.3157\% for each condition).

In regard of the above co-existing conditions, Gastroenteritis with or without dehydration is the main coexisting condition followed by Respiratory Tract Infections combined (Pulmonary Tuberculosis, Pneumonia, Bronchopneumonia and URTI).

\section{Does Severe Malnutrition being costly regarding the duration of admission (stay) in the hospital of severe malnourished children?}

According to the data collected, the shortest time spent at the Pediatric Ward by a child is less than a full day while the longest time spent at the Pediatric Ward was 27 days spent at the Pediatric Ward.

The average time that a child with malnutrition spends was: 770 days (Total number of days spent by all the 76 children in the hospital): 76 (Number of children with severe malnutrition) which equals to 10 days 3hours and 9minutes and 28 seconds.

The average stay among the children who have died is: (211days:21) $=10$ days 1 hour 8 min and 34 seconds.

The average stay among the children who have survived is (559days: 55 ) $=10$ days 3 hours 55minutes and 38 seconds. 
This shows that it is costly to treat Severe Malnutrition as children stay longer up to a maximum of 27 days.

\section{Charts and tables of different data analysis}

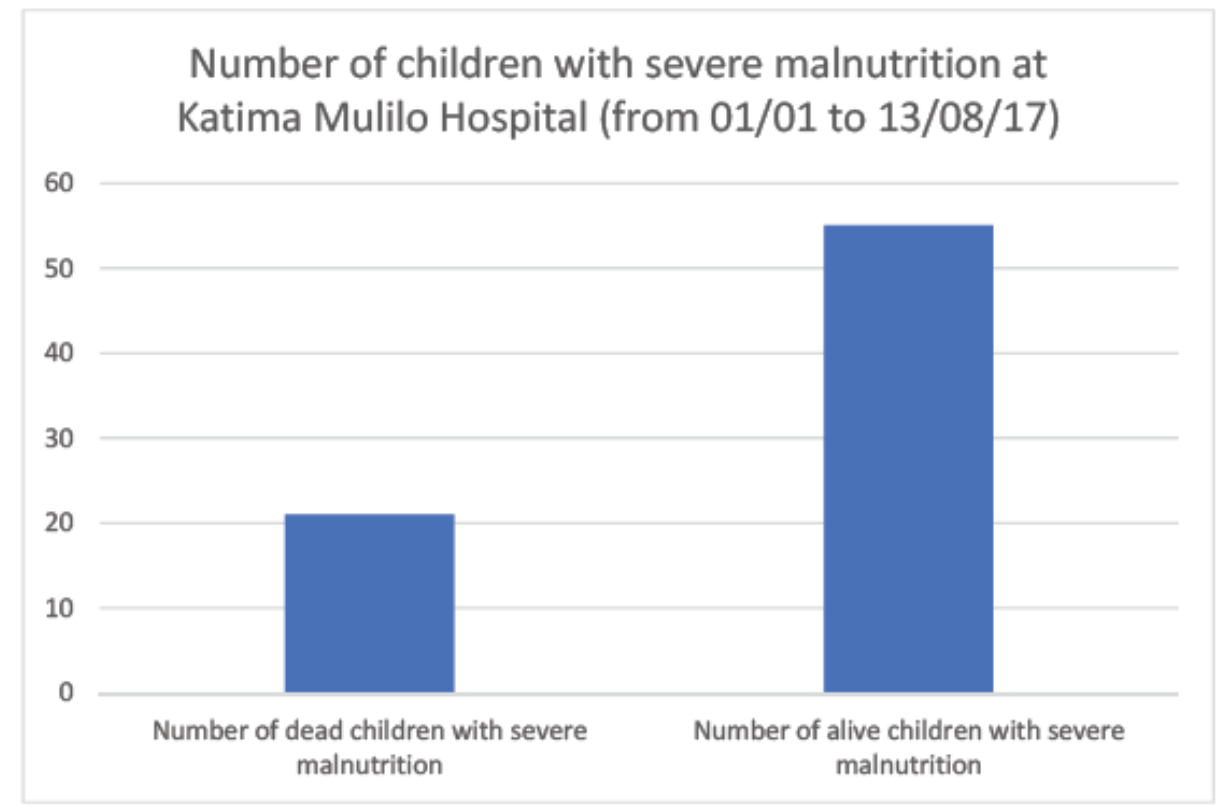

Figure 1. Number of children who have died and those who survived

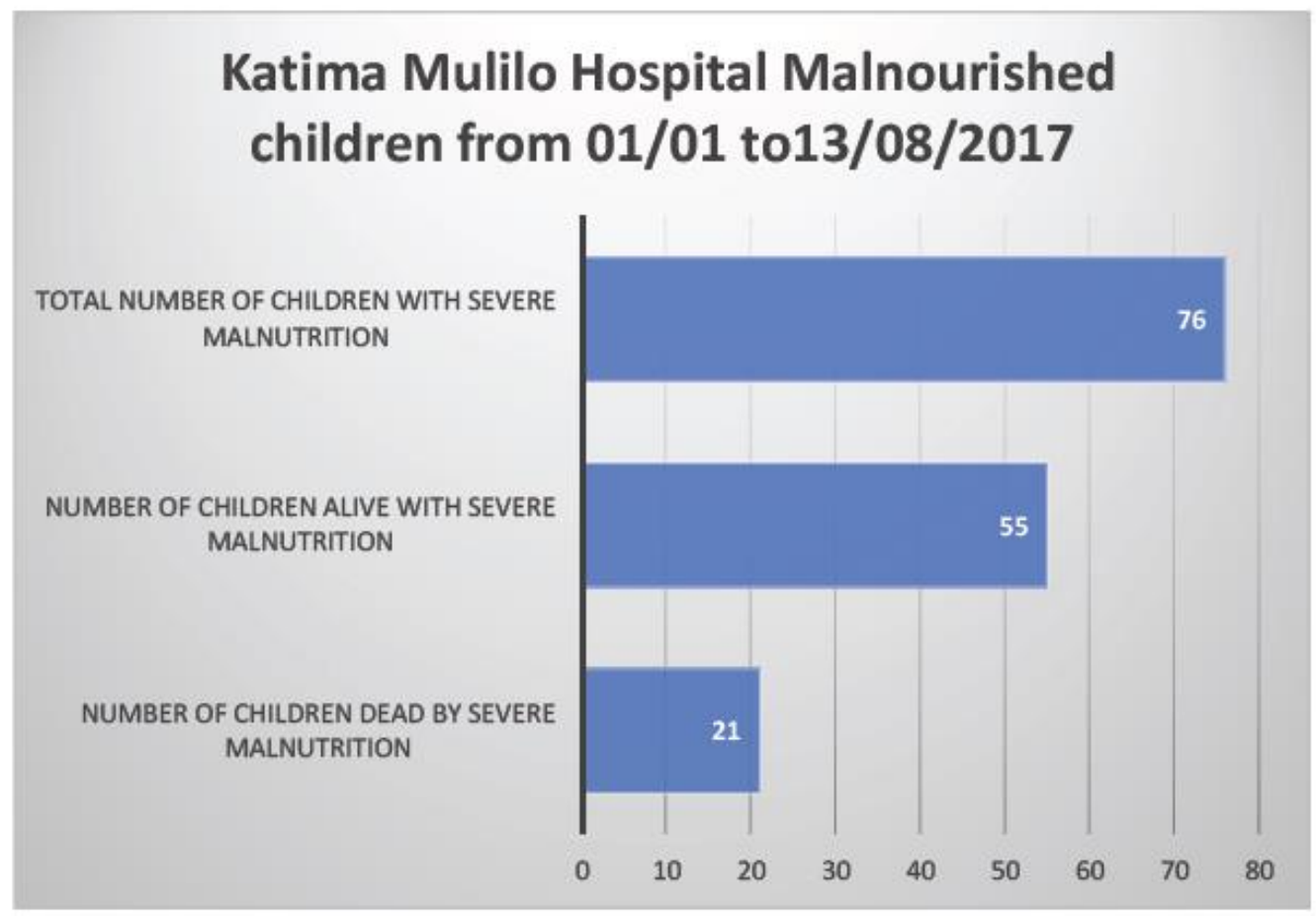

Figure 2. Katima mulilo hospital malnourished children based on the gender 
DOI: $10.21522 /$ TIJPH.2013.05.04.Art019

ISSN: $2520-3134$
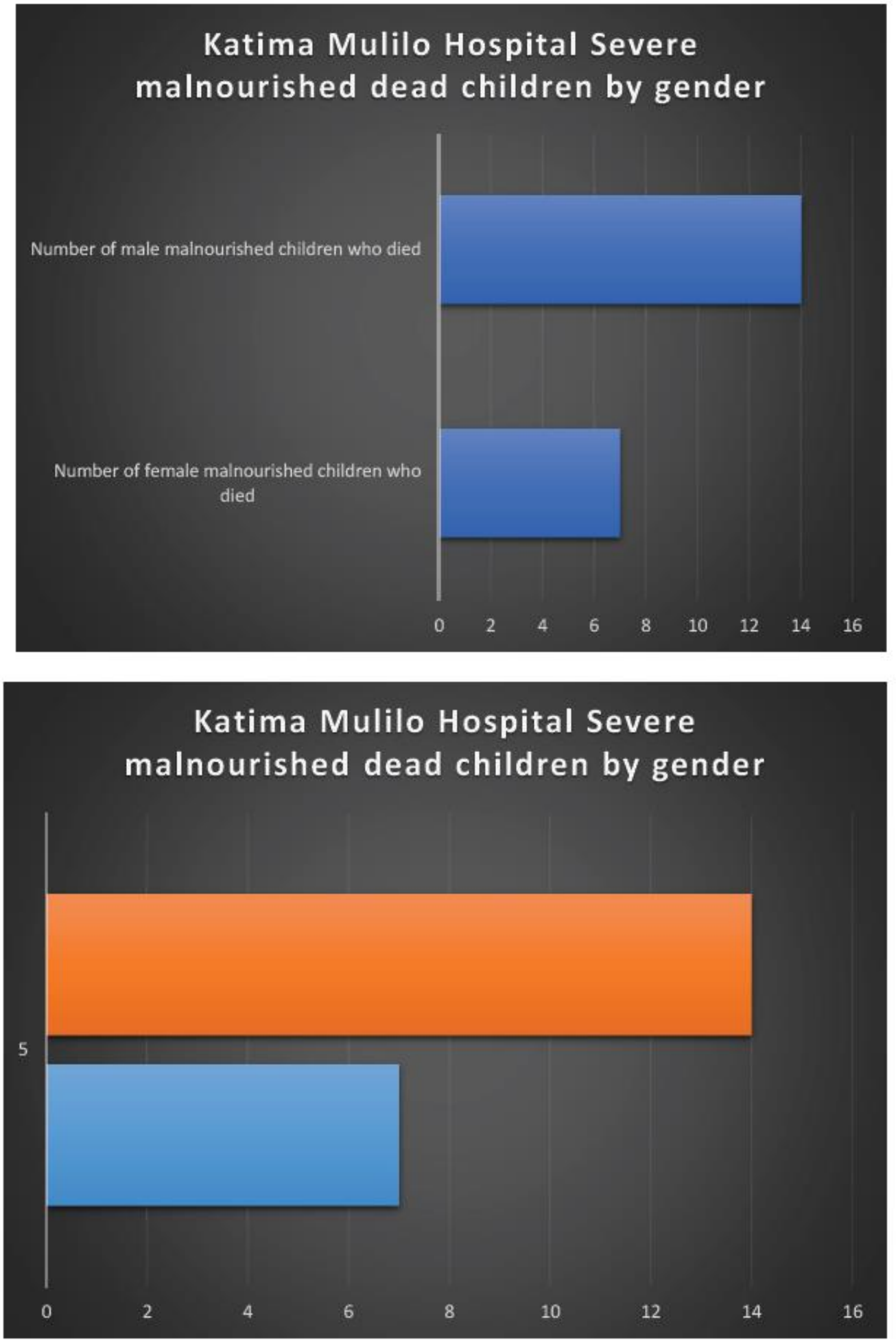

Figure 3. Alive severe malnourished children by gender 


\section{Number of severe malnourished alive children by} gender

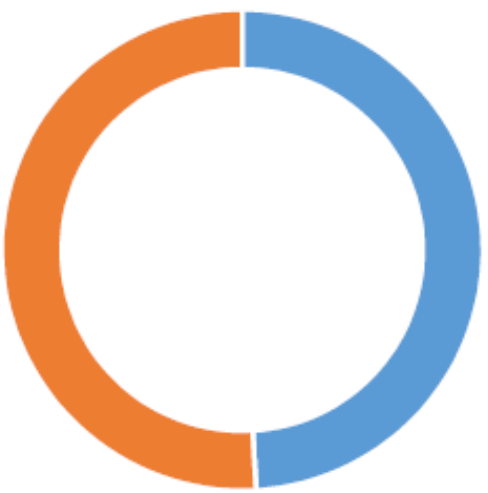

- Number of female children malnourished who survived

- number of male children malnourished who survived

Figure 4. Number of severe malnourished dead children based on their HIV Status

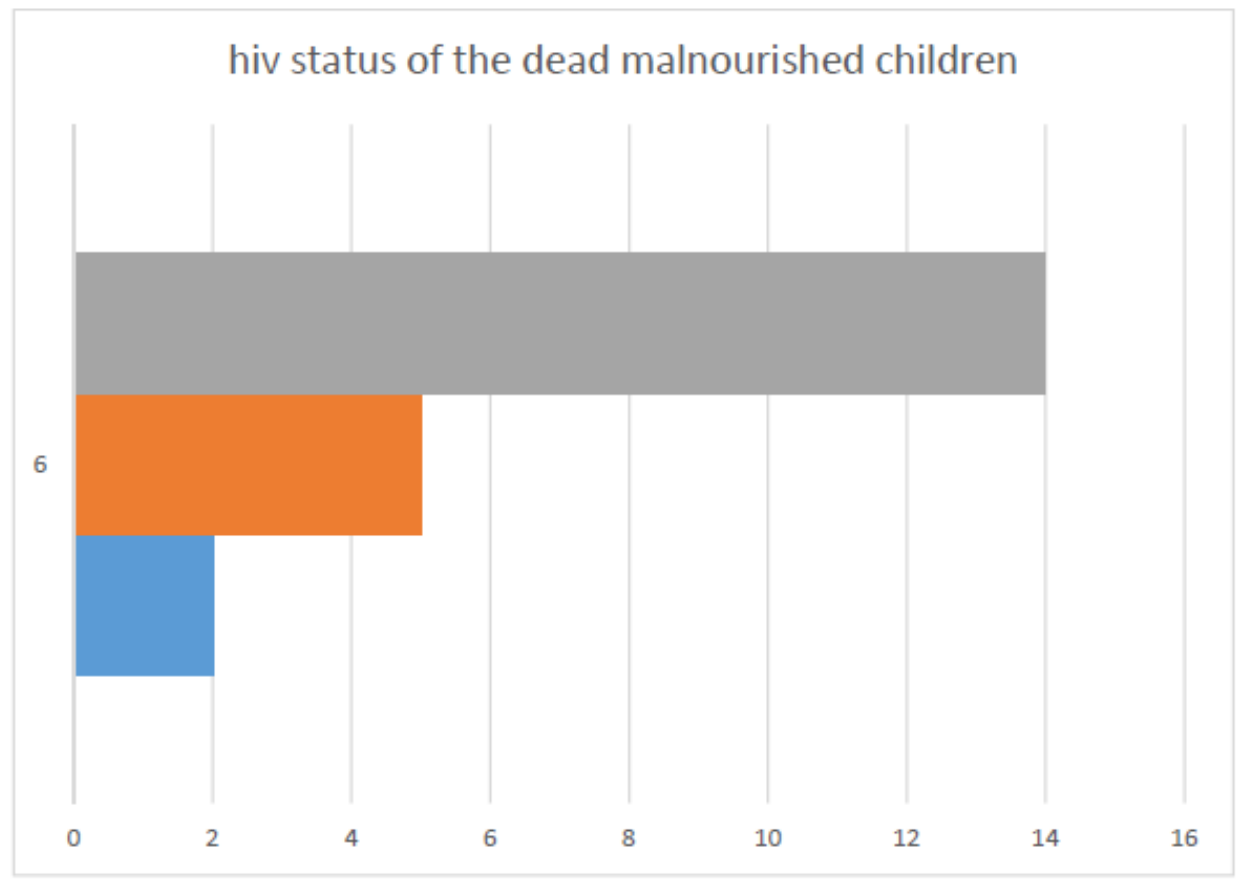

Figure 4. HIV status of the dead malnourished children

\section{Findings and conclusions}

The study has shown that:

1. Katima Mulilo district Hospital has a mortality rate which is not acceptable (27.63\%) among children with severe Malnutrition. By extension, the whole Zambezi Region has high rate of Severe Malnutrition (Wasting). 
DOI: $10.21522 / \mathrm{TIJPH} .2013 .05 .04$. Art019

ISSN: $2520-3134$

2. Male children are more fragile than Female Children in front of Severe Malnutrition. 2 male children for 1 female child are dying of severe wasting.

3. Literature has clearly stated that patients with HIV worsens the malnutrition condition but during this study, there was no significant difference between Severe malnutrition in children with HIV and severe malnutrition in children.

4. Gastroenteritis is the most co-existing condition with Severe Malnutrition.

5. Indeed, $50 \%$ of children with severe malnutrition are suffering of Gastroenteritis.

6. The longest stay in the hospital for children with severe malnutrition is 27 days and the average (median) of staying for children with severe malnutrition is 10 days 3hours and 9 minutes.

7. In conclusion,

8. Severe malnutrition is a real problem of Public health in Katima Mulilo and in Zambezi Region by extension. This shows that despite being part of Southern Africa, the Republic of Namibia through the Zambezi Region has also a problem of Severe Malnutrition that is not acceptable in regard to the criteria (cut-off value) of World Health Organization (WHO). This is not a problem only for Central Africa Countries but also some part of the Southern Africa such as Zambezi Region in Namibia. It is also important to take note that in these data, children who are brought dead from different of Zambezi Region and those who are not seeking help at the clinics or the hospital but go to seek help to the herbalists and traditional healers are missing in these data collected. In other words, these data might be under representative.

9. All the means to prevent severe malnutrition to occur has to be taken and implemented.

10. Male children are more vulnerable than female Children with Severe Malnutrition.

11. HIV infection as well as Severe Malnutrition needs more awareness in order to reduce the risk of HIV Infection and to reduce the issue of severe malnutrition.

12. The prevention and treatment of other co- existing conditions (such as Gastro enteritis, Pulmonary Tuberculosis...) with severe malnutrition is very crucial in the outcome of the management of severe malnutrition.

13. Prevention is better than cure. There is a need to put in place strategies with the support of NGOs (Non-Governmental Organizations) that will enable to identify areas where malnutrition is very endemic in order to help financially and through Health Education to reduce or alleviate the problem of Severe Malnutrition (wasting).

\section{References}

[1]. African Economic Outlook, AFDB/OECD 2008

http://www.oecd.org/dev/emea/40578314pdf

[2]. Global Nutrition Policy Review: What does it take to scale up nutrition action?, World health Organization (WHO), 2013.

[3]. Guidelines for the Inpatient Treatment of severely malnourished children, page 25, An Ashworth. Et. Al, WHO Library Cataloguing-in-Publication Data, WHO, 2003

[4]. Levels \& Trends in Child Malnutrition Unicef-WHO-The World Bank Joint Child Malnutrition Estimates; 2012.

[5]. Namibia Standard Treatment Guidelines, Ministry of health and Social Services of Namibia, page 579, 2011.

[6]. Namibia Standard Treatment Guidelines, Ministry of Health and Social Services of Namibia, pp: 579-581, 2011.

[7]. Namibia Standard Treatment Guidelines, Ministry of Health and Social Services of Namibia, pp: 620 -622, 2011.

[8]. Nutrition Landscape Information System (NLIS) Country Profile Indicators: Interpretation guide, WHO, 2010.

[9]. National HIV Sentinel Survey 2016, Ministry of Health and Social Services, Government of Namibia.

[10]. Nutrition \& HIV AIDS; Evidence, Gaps and Priority for International Development (USAID), April 2004.

[11]. Namibia 2011 Population \& Housing Census Main Report, Namibia Statistics Agency, Namibia Population \& Housing Census; Republic of Namibia.

[12]. UNICEF, WHO, World Bank Group joint Malnutrition estimates; 2015 Edition, www.who.int/ Nutrition; data. unicef.org data worldbank. 
Texila International Journal of Public Health Volume 5, Issue 4, Dec 2017

[13]. Zambezi Regional and Local Economic Strategy 2015-2016, Magreth Hausiku, Niron Michaels, Zambezi Regional Council, 2014. 